\title{
Cardiac Myxomas: A Histodemographic Analysis
}

\author{
Afia Akhter ${ }^{1}$, Nadira Majid², Syed Salahuddin Ahmed³ ${ }^{3}$ Kuazi Dil Afroz ${ }^{4}$, \\ Md. Rezwanur Rahman ${ }^{5}$, Syed Mukarram Ali6
}

\begin{abstract}
Background: Cardiac myxoma is the most common benign cardiac tumour, accounting for more than half of all primary cardiac tumours. Most myxomas are sporadic and the cause is largely unknown. Familial variants with an autosomal dominant inheritance exist. It is localized generally in the left atrium and typically develops in females. Clinical manifestations can mimic cardiac conditions and depend on the natural behaviour of the tumour and its location within the heart, ranging from being completely asymptomatic to causing sudden death. Establishing an early diagnosis is essential, which is confirmed by histopathology. Objective: The aim was to find the relation between cardiac myxomas with age, sex and cardiac sites. Materials and method: This cross sectional study was done in the pathology department of Delta Hospital Limited, Dhaka, Bangladesh, during the period of January 2014 to July 2016. A total of 24 cases were studied irrespective of age, sex along with clinical diagnosis. Results: Among the study subjects females were predominant $(70.83 \%)$ and highest frequency of cases occurred in between 41-50 years of age (41.67\%). Commonest site was left atrium (83.33\%). Conclusion: The present study revealed that cardiac myxoma occurs most commonly in the 5th decade with female predominance and the most common site is left atrium.
\end{abstract}

Keywords: Cardiac myxomas; demography; histopathology.

Delta Med Col J. Jan 2018;6(1):4 - 8

\section{Introduction}

Myxoma of heart is the commonest intra-cavitary cardiac tumour. ${ }^{1,2}$ The clinical manifestations of these tumours are variable and despite the increase of clinical awareness and improved diagnostic techniques, still their diagnosis occasionally appears as a surprise at surgery or autopsy. ${ }^{3-5}$ Also, despite several histochemical and structural studies of cardiac myxomas, the cell of origin and certain of the structural features of these tumours remain subject of controversy. ${ }^{6-12}$

1. Associate Professor, Dept. of Pathology, Delta Medical College, Dhaka, Bangladesh.

2. Associate Professor, Dept. of Pathology, Delta Medical College, Dhaka, Bangladesh.

3. Senior Consultant (Histopathology), Delta Hospital Ltd, Dhaka, Bangladesh.

4. Consultant (Histopathology), Delta Hospital Ltd, Dhaka, Bangladesh.

5. Professor, Dept. of Biochemistry, Delta Medical College, Dhaka, Bangladesh.

6. Professor of Pathology.

Correspondence: Dr. Afia Akhter. e-mail: aakhter31@gmail.com 
Most cases of myxomas are sporadic. Approximately $10 \%$ are familial and are transmitted in an autosomal dominant mode. ${ }^{13,14}$ At present the Carney complex is used to describe an autosomal dominant trait, that includes cardiac myxomas, cutaneous myxomas, spotty pigmentations on the skin, endocrinopathy and both endocrine and non-endocrine tumours. ${ }^{15}$ These patients are considerably younger at the time of diagnosis when compared to patients with sporadic myxomas. ${ }^{16}$

Myxomas are polypoid, round or oval. They are gelatinous with a smooth or lobulated surface and usually are white, yellowish or brown.

Approximately $75 \%$ are located in the left atrial cavity at the fossa ovalis, $23 \%$ in the right atrial cavity and about $2 \%$ in the ventricular cavity. ${ }^{16,17}$ The cells arise from multipotential mesenchymal cells and are characterized as lipidic cells embedded in a vascular myxoid stroma. ${ }^{16}$

The light microscopic study of resected tumours revealed abundant mucoid stroma, varied cellularity from area to area along with areas of fibrosis and haemorrhage. The myxoma cell, singly or in clumps, lay in pools of mucoid stroma and they vary in shape from round to spindle to stellate. ${ }^{18,19}$

The histochemical studies showed that the tumour's ground substance is composed of only hyaluronic acid and chondroitin-4 or chondroitin- 6 sulphate. ${ }^{20}$

While small myxomas can be asymptomatic, the majority may present with one or more of the triad of intracardiac obstruction, cardioembolism and/or non specific constitutional manifestations. The clinical presentation varies depending upon the physical behaviour of the tumour and its location within the heart. ${ }^{20}$ Obstruction of the circulation through the heart or heart valves commonly gives rise to symptoms of left (dyspnea, recurrent pulmonary oedema, paroxysmal nocturnal dyspnea, orthopnea) or right sided (peripheral oedema, ascitis, fatigue, hepatomegaly) heart failure, often mimicking mitral or tricuspid stenosis. ${ }^{21}$ Embolisation which occurs in $30-40 \%$ of myxomas is usually systemic but may also be pulmonary. ${ }^{16}$ Constitutional or systemic symptoms such as fatigue, fever, rashes, joint pains and weight loss can also be seen.

Laboratory abnormalities are usually seen as elevated inflammatory markers such as ESR, serum C-reactive proteins and globulin levels as well as anaemia and high serum interleukin-6 (IL-6) levels. ${ }^{16,22}$ Sometimes low grade but long standing fever can be the only symptom. ${ }^{23}$

Once the diagnosis of cardiac myxoma has been made, the patient should be operated upon as soon as possible before undesirable complication, embolization or sudden death occurs. An 8\% mortality has been reported in patients awaiting operation following definitive diagnosis. ${ }^{20}$

Different studies on age and sex distribution relating cardiac myxoma explored that cardiac myxomas are the most common benign primary cardiac tumours in adult. ${ }^{24}$ They are three times more common in females and $90 \%$ diagnosed in the fourth to sixth decades of life. ${ }^{25,26}$ They are rarely seen in children, in whom they constitute $15 \%$ of cardiac tumours. ${ }^{25,27,28}$ They can be seen anywhere in the heart, but arise most commonly in the left atrium $(60-80 \%) .{ }^{25,29}$

Our aim was to find the relation of cardiac myxomas with age, gender and cardiac site in our population.

\section{Materials and method}

This cross-sectional study was done on 24 specimens of cardiac tumour biopsy from subjects, irrespective of age and sex from January 2014 to July 2016 in the pathology laboratory of 
Delta Hospital Limited, Dhaka, Bangladesh. The specimens were received in $10 \%$ formalin as a routine procedure. Paraffin blocks were embedded from each of the specimen and processed in the automatic tissue processor and cut about the thickness of 4 micron and stained with Haematoxylin and Eosin stain for histopathological diagnosis.

Data were analyzed by SPSS for Windows Version 19.0 and the results were expressed as proportion.

\section{Gross picture of myxoma}

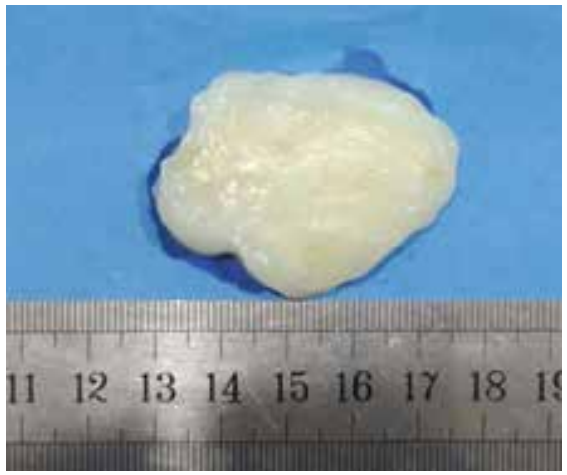

Fig 1: Typical gross appearance of myxoma showing myxoid cut surface

\section{Microscopic pictures of myxoma}

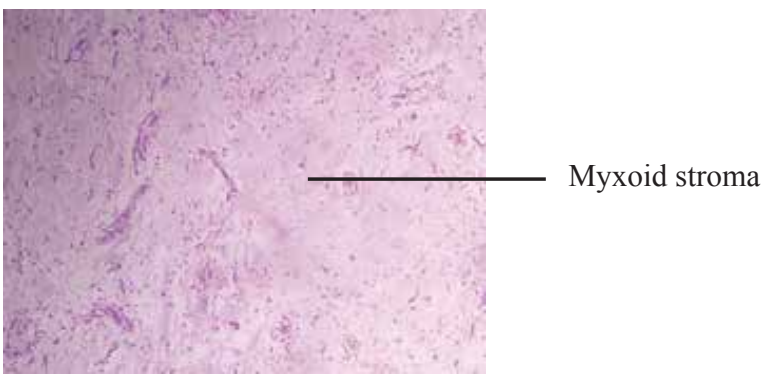

Fig 2: Microscopic picture of myxoma (Low power view)

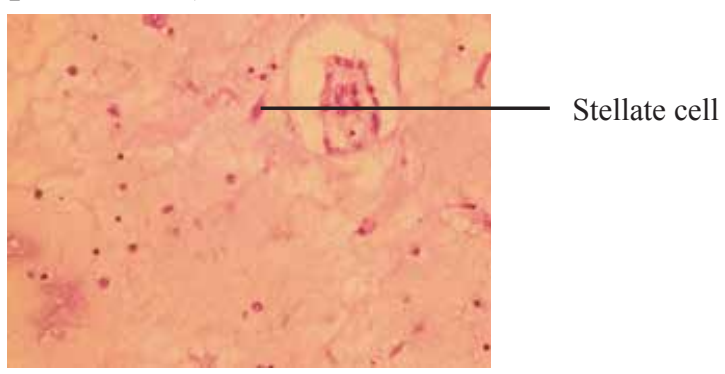

Fig 3: Microscopic picture of myxoma (High power view)

\section{Results}

A total 24 cases of both sex were enrolled in the study. The study was aimed at assessing the relation between cardiac myxoma with two major demographic variables, age and sex and also with anatomic site of heart.

Table I shows that $29.16 \%$ male and $70.84 \%$ female has Cardiac myxomas.

Table I: Sex distribution ( $\mathrm{N}=\mathbf{2 4})$

\begin{tabular}{lcc}
\hline Sex & Frequency & Percentage \\
\hline Male & 7 & 29.16 \\
Female & 17 & 70.84 \\
\hline
\end{tabular}

Table II shows majority of the myxomas occur in the left atrium $(83.33 \%)$.

Table II: Site of distribution $(\mathrm{N}=\mathbf{2 4})$

\begin{tabular}{lcc}
\hline Site & Frequency & Percentage \\
\hline Left atrium & 20 & 83.33 \\
Right atrium & 3 & 12.5 \\
Left ventricle & 1 & 4.17 \\
\hline
\end{tabular}

Table III shows majority of the myxomas occur in 5th decade (41.67\%).

Table III: Age distribution ( $\mathrm{N}=\mathbf{2 4})$

\begin{tabular}{lcc}
\hline Age in years & Frequency & Percentage \\
\hline$<20$ & 1 & 4.17 \\
$20-30$ & 2 & 8.33 \\
$31-40$ & 5 & 20.83 \\
$41-50$ & 10 & 41.67 \\
$51-60$ & 5 & 20.83 \\
$>60$ & 1 & 4.17 \\
\hline
\end{tabular}

Table IV shows most female patients in the 5th decade and male patients in the 6th decade.

Table IV: Mean age distribution in both sex

\begin{tabular}{lcc}
\hline Sex & Mean & Std. Deviation \\
\hline Male $(\mathrm{n}=7)$ & 53.1667 & 7.35980 \\
Female $(\mathrm{n}=17)$ & 41.2941 & 12.87325 \\
\hline
\end{tabular}




\section{Discussion}

Myxoma of heart is the commonest primary cardiac tumour. They are three times more common in females and $90 \%$ diagnosed in the fourth to sixth decades of life. ${ }^{25,26}$ They can be seen anywhere in the heart, but arise most commonly in the left atrium (60-80\%). ${ }^{25,29}$

The present study shows $70.83 \%$ cardiac myxomas occur in female and male to female ratio is 1:2.43. Similar studies had been done previously. A study in China with an observation period of 2007-2012, showed male to female ratio was 1:1.54, which represented female predominance. ${ }^{30}$ Another study by Zheng et al. ${ }^{31}$ among a series of 66 cardiac myxomas also reported similar results regarding gender distribution of myxoma, where male to female ratio was 1:2.7. A study by King showed female predominance in cardiac myxomas. ${ }^{13}$ Two other studies showed that cardiac myxomas are three times more common in females. ${ }^{25,26}$ All the results are very close to the present study but do not reflect the exact scenario of sex distribution. The possible explanation may be the very low number of myxoma patient was included in this study.

The present study demonstrated that the highest incidence of myxoma is in the 5th decade with most female patients also in the 5th decade and most male patients are in the 6th decade. Panagiotis et al. with an observation period of 1963-1975 reported the highest incidence was in between 30-60 years which was a wide range in respect to the present study. ${ }^{20} \mathrm{~A}$ similar study done in China reported the highest incidence to be in the 48.8 years and 51.9 years, that is in the 5 th and 6 th decades in female and male respectively, which was very close to the present study. ${ }^{30}$ Another study by Aggarwal et al. which showed the mean age for cardiac myxoma is 56 years. $^{32}$ The possible explanation for this discordance is that the previous studies, where sample size was larger than the present one, which is a hospital based study.
In the present study $83.33 \%$ of myxomas occured in left atrium and $12.5 \%$ occured in right atrium and remaining were in the left ventricle. Many similar results were found previously through many studies. Larsson et al. showed that $75-85 \%$ of cardiac myxomas occur in left atrial cavity and upto $25 \%$ occur in right atrium. ${ }^{33}$ Another study by Wang et al. shows $88.5 \%$ cardiac myxomas occur in left atrial cavity, $9.8 \%$ in right atrium and $1.7 \%$ in right ventricle. ${ }^{30}$

\section{References}

1. Abbott OA, Warshawski FE, Cobbs BW. Primary Tumors and Pseudotumors of the Heart. Ann Surg. 1962;155:855.

2. Prichard RW. Tumors of the Heart: Review of the Subject and Report of 150 Cases. Arch Pathol. 1951;51:98.

3. Cooley DA, Morris GC, Jr., Attar S. Cardiac Myxoma. Arch Surg. 1959;78:410.

4. Emanuel RW, Lloyd WE. Right Atrial Myxoma Mistaken for Constrictive Pericarditis. Br Heart J. 1962;24:796.

5. Willman VL, Symbas PN, Mamiya RT, Cooper T, Hanlon CR. Unusual Aspects of Intracavitary Tumors of the Heart. Report of Two Cases. Dis Chest. 1965;47:669.

6. Fine G, Morales A, Horn RC. Cardiac Myxoma. A Morphologic and Histogenetic Appraisal. Cancer. 1968;22:1156.

7. Fisher ER, Hellstrom HR. Evidence in Favor of the Neoplastic Nature of Cardiac Myxoma. Am Heart J. 1960;60:630.

8. van den Berg C, Block APR. Myxoma Cordis. Some Morphological and Enzyme-Histochemical Aspects. Path Europ. 1966;1:3.

9. Matsuyama K, Ooneda G. Histogenesis of Primary Myxoma of the Heart: A Case Report. Gann. 1967;58:435.

10. Silverberg SG, Kay S. Ultrastructure of a Cardiac Myxoma. Am J Clin Pathol. 1970;54:650. 
11. Williams WJ, Jenkins D, Erasmus D. The Ultrastructure of Cardiac Myxoma. Thorax. 1970;25:756.

12. Zuidema GD, Burke JF, Villegas AH, Scannell JG. Surgery of Atrial Myxoma. N Engl J Med. 1961;264:1016.

13. King TW. On Simple Vascular Growth in the Left Auricle of the Heart. Lancet. 1845;2:428-29.

14. Basson CT, MacRae CA, Korf B. Genetic Heterogeneity of Familial Atrial Myxoma Syndromes (Carney Complex). Am J Cardiol. 1997;79(7):994-95.

15. Imai Y, Taketani T, Maemura K, Takeda N, Harada T, Nojiri T. Genetic Analysis in a Patient with Recurrent Cardiac Myxoma and Endocrinopathy. Circ J. 2005;69(8):994-95.

16. Reynen K. Cardiac Myxomas. N Eng J Med. 1995;333:1610-17.

17. Roberts WC. Primary and Secondary Neoplasms of the Heart. Am J Cardiol. 1997;80:671-82.

18. Amano J, Kono T, Wada Y, Zhang T, Koide N, Fujimori M, et al. Cardiac Myxoma: Its Origin and Tumour Characteristics. Ann Thorac Cardiovasc Surg. 2003;9(4):215-21.

19. Lloreta J, Juanpere N, Riverola A, Dallari D, Cañas MA, Pijuan L, et al. Cardiac Myxoma with Glandular Differentiation: An Immunohistochemical and Ultrastructure Study. Ultrastructural Pathology. 2013;37(1):77-82.

20. Panagiotis NS, Charles RH, Jr., Michael BG. Myxoma of the Heart. Ann Surg. 1976; 183(5):470-74

21. Ahraaz W. A Look at Cardiac Myxoma. UWOMJ 2008;77(2):63-66.

22. Mendoza CE, Rosado MF, Bernal L. The Role of Interleukin-6 in Cases of Cardiac Myxoma. Clinical Features, Immunologic Abnormalities and a Possible Role in Recurrence. Tex Heart Inst J. 2001;28(1):3-7.

23. Gavrielatos G, Letsas KP, Pappas LK, Dedeilias P, Sioras E, Kardaras F. Large Left Atrial Myxoma
Presented as Fever of Unknown Origin: A Challenging Diagnosis and a Review of the Literature. Cardiovascular Pathology. 2007;16: 365-67.

24. Schroeder S, Achenbach S, Bengel F, Burgstahler C, Cademartiri F, de Feyter P, et al. Cardiac Computed Tomography: Indications, Applications, Limitations, and Training Requirements: Report of a Writing Group Deployed by the Working Group Nuclear Cardiology and Cardiac CT of the European Society of Cardiology and the European Council of Nuclear Cardiology. Eur Heart J. 2008;29(4):531-56.

25. Butany J, Nair V, Naseemuddin A, Nair GM, Catton C, Yau T. Cardiac Tumors: Diagnosis and Management. Lancet Oncol. 2005;6:219-28.

26. Yoon DH, Roberts W. Sex Distribution in Cardiac Myxomas. Am J Cardiol. 2002;90:563-65.

27. Jain D, Maleszewski JJ, Halushka MK. Benign Cardiac Tumors and Tumor like Conditions. Ann Diagn Pathol. 2010;14:215-30.

28. Uzun O, Wilson DG, Vujanic GM, Parsons JM, de Giovanni JV. Cardiac Myxomas in Children. Orphanet J Rare Dis. 2007;2:11.

29. Reynen K. Cardiac Myxomas. N Engl J Med. 1995;333:1616-17.

30. Wang J, Li Y, Liu H, Li NN, Zhao J, Xing XM. Clinicopathologic Analysis of Cardiac Myxomas: Seven Years' Experience with 61 Patients. J Thorac Dis. 2012;4(3):272-83.

31. Yu k, Liu Y, Wang H, Hu S, Long C. Epidemiological and Pathological Characteristics of Cardiac Tumors: A Clinical Study of 242 Cases. Interact Cardiovasc Thorac Surg. 2007;6:636-39.

32. Aggarwal SK, Barik R, Sarma TC, Lyer VR, Sai V, Mishra J. Clinical Presentation and Investigation Findings in Cardiac Myxomas: New Insights from the Developing World. Am Heart J. 2007;154(6):1102-1107.

33. Larsson S, Lepore V, Kennergren C. Atrial Myxomas: Results of 25 Years' Experience and Review of the Literature. Surgery. 1989;105(6):695-98. 